УДК 338.462:338.45

ББК 65.01

ЗНАЧЕНИЕ УСЛУГ ПРОМЫШЛЕННОГО ХАРАКТЕРА В ПОВЫШЕНИИ

КОНКУРЕНТОСПОСОБНОСТИ ПРОМЫШЛЕННЫХ ПРЕДПРИЯТИЙ

(В КОНТЕКСТЕ ЧЕТВЕРТОЙ ПРОМЫШЛЕННОЙ РЕВОЛЮЦИИ)*

\author{
Ю. В. МЕЛЕШКО \\ meleshkojv@gmail.com \\ аспирант кафедры «Экономика и право» \\ Белорусский национальный технический университет \\ г. Минск, Республика Беларусь
}

\begin{abstract}
Статья посвящена проблематике услуг промышленного характера, а именно изменению их роли в промышленном производстве в контексте четвертой промышленной револючии. Выделены факторы роста сферы услуг, приведчие к доминированию этого сектора в структуре мирового ВВП и занятости. На основании статистических данных проведен анализ кризисоустойчивости различных видов экономической деятельности. Показан механизм роста сферы услуг промышленного характера в условиях реиндустриализачии за счет организации эффективного производства нового типа («умные заводы») и реализачии клиентоориентированной политики предприятий промылиленности.
\end{abstract}

Ключевые слова: промышленная политика, реиндустриалицация, техникотехнологический прогресс, конкурентоспособность, сфера услуг, услуги промышленного характера.

\title{
THE IMPORTANCE OF INDUSTRIAL CHARACTER SERVICES IN IMPROVING THE COMPETITIVENESS OF INDUSTRIAL ENTERPRISES (IN THE CONTEXT OF THE FOURTH INDUSTRIAL REVOLUTION)
}

\author{
J. V. MELESHKO \\ post-graduate student of the department «Economics and Law» \\ Belarusian National Technical University \\ Minsk, Republic of Belarus
}

The article is devoted to the problems of industrial services, namely, to changing their role in industrial production in the context of the fourth industrial revolution. Factors of growth in the sphere of services, which led to the dominance of this sector in the structure of world GDP and employment, are singled out. On the basis of statistical data, the analysis of the crisesworthiness of various types of economic activity was carried out. The mechanism of growth of the sphere of industrial services in the conditions of reindustrialization is shown through the organization of effective production of a new type ("smart plants") and the implementation of a customer-oriented policy of industrial enterprises.

Keywords: industrial policy, reindustrialization, technological and technological progress, competitiveness, services, industrial services.

\footnotetext{
* Статья подготовлена в рамках договора с БРФФИ №Г17М-017 от 18.04.2017 г.
} 


\section{ВВЕДЕНИЕ}

Услуги промышленного характера как объект изучения отличаются высокой динамичностью. Происходит постоянное уточнение понятийного аппарата, выявление новых закономерностей, в ряде случаев приходится отказываться от ранее выявленных, поскольку тренды также быстро меняются. Это связано, во-первых, с изменениями техники и технологий промышленного производства и сменой технологических укладов, во-вторых - с изменением условий хозяйствования.

Ранее нами уже исследовался этот феномен, в результате чего мы получили следующие выводы. Услуги промышленного характера относятся к бизнес-услугам и направлены на «удовлетворение потребностей предприятий промышленного комплекса, повышение конкурентоспособности промышленной продукции путем совершенствования производственного процесса на протяжении всей цепочки создания стоимости, включая: инжиниринг, менеджмент, маркетинг, логистику и т.д.» [1, с. 120]. В экономической литературе понятие «услуга промышленного характера» (англ. Industrial Service, нем. industrienahe Dienstleistung, industrielle Dienstleistung) встречается в узкой и широкой трактовках. В узком смысле под этой услугой понимается оказание предприятием промышленности по заказу услуг по переработке, обработке, ремонту и т.д. При расширенной трактовке услуга промышленного характера понимается не только как специфический вид услуги, оказываемой промышленным предприятием сторонней организации, а как деятельность, связанная с разработкой, производством, реализацией или послепродажным обслуживанием продукции предприятий промышленного комплекса. Придерживаясь второго подхода к пониманию рассматриваемых услуг, было предложено следующее определение: услуга промышленного характера «хозяйственного блага в форме действия, обеспечивающего создание, развитие и функционирование технологий, связанных с разработкой, производством, реализацией и сервисным обслуживанием промышленной продукции» [2, с. 84].

Характерные черты услуг промышленного характера, как межотраслевой характер, специализация на промышленном производстве, круг субъектов, предопределяют специфический экономический механизм их оказания. При этом под экономическим механизмом оказания услуг промышленного характера понимается «комплекс мер (формы, методы, инструменты хозяйствования, организационно-управленческие и социально-экономические отношения) по развитию и устойчивому функционированию услуг промышленного характера с целью обеспечения роста конкурентоспособности национального промышленного комплекса и промышленных предприятий» [3, с. 59]. С помощью экономических форм, методов и инструментов хозяйствования субъекты реализуют свои разнообразные экономические интересы в определенных исторических формах. Традиционными формами оказания услуг промышленного характера являются внутренние услуги, аутсорсинг и инсорсинг, при этом наибольшее распространение получили такие инструменты, как трудовой договор, договор подряда и т.д. По мере развития (качественного и количественного) услуг промышленного характера изменяется и экономический механизм их оказания: все больше услуг перестают быть внутренними и в соответствии с глобальной тенденцией к расширению все чаще становятся внешними. Таким образом, услуги промышленного характера выделяются из производственного комплекса и передаются отдельным специализированным предприятиям, чья деятельность связанна с промышленным производством или промышленной продукцией, относящимся, как правило, к сфере услуг.

Приведенные выводы, однако, нуждаются в уточнении, особенно с учетом динамики в целом мировой экономики и экономики Республики Беларусь в частности. 
Так, С. Ю. Солодовников пишет: «В последние десятилетия в мире произошли радикальные технологические изменения, по своему влиянию на эволюцию человечества сопоставимые только с неолитической революцией и с эпохой Великих географических открытий» $[4$, с. 6$]$. Складывающиеся современные хозяйственные отношения принципиально отличаются от классических рыночных или социально-ориентированных рыночных, также как и от плановой экономики. С. Ю. Солодовников для обозначения нового типа экономической системы использует понятие «пострыночная экономика» и отмечает, что для нее характерно наличие высокоэффективного промышленного производства, значительное увеличение доли сектора услуг в ВВП, дальнейшее увеличение значения знаний для развития экономики, развитие интернет-технологий и новые (пострыночные) формы конкурентной борьбы» [5, с. 23]. В условиях социальноэкономической глобализации меняется характер конкуренции: «социально-экономические субъекты, стремящиеся к господству в планетарном масштабе или к доминированию в крупных регионах, для оптимизации условий своей экспансии предпринимают значительные (в том числе и финансовые) усилия для уничтожения культурного, человеческого, административного и социального капитала в социальноэкономических системах - объектах проникновения» [6, с. 49]. При этом социальные факторы уже не воспринимаются как «дополнительные трансакционные издержки», а как «основа функционирования любой национальной экономической модели» [7, с. 25].

Совершенствование экономического механизма оказания услуг промышленного характера должно быть направлено, прежде всего, на повышение адаптивности к новым внешним условиям. Традиционные методы и инструменты оказания услуг промышленного характера, которые были весьма эффективны 10 лет назад, могут быть применены сегодня лишь частично. Республика Беларусь - молодое динамично развивающееся государство с малой открытой экономикой. Так, С. Ю. Солодовников и др. справедливо отмечают, что экономическая система Беларуси «функционирует в условиях диалектического единства общего и частного: реальные экономические отношения у нас развиваются под воздействием универсальных экономических законов и закономерностей, трансформирующихся под влиянием уникальных белорусских институциональных особенностей» [8, с. 10]. Социально-экономическое развитие нашей страны происходит под влиянием как внутренних, так и внешних факторов, а уникальные институциональные особенности требуют нового уточнения направлений и инструментов развития экономического механизма оказания услуг промышленного характера.

\section{РЕЗУЛЬТАТЫ И ИХ ОБСУЖДЕНИЕ}

По справедливому замечанию Т. В. Сергиевич, «все сферы совокупного общественного производства в своем единстве, продиктованном, во-первых, необходимостью в постоянном обмене результатами труда, а во-вторых, тем фактом, что в реальном мире они практически не встречаются в «чистом» виде, сохраняют некую относительную автономность и противоречивость» [9, с. 284]. Тенденция сокращения доли промышленного производства при одновременном увеличения доли сектора услуг в структуре ВВП и занятости, начавшаяся в середине 1950-ых гг. в США, сегодня носит глобальный характер и затрагивает не только наиболее экономически развитые страны (США, Германия, Япония, Великобритания), но и развивающиеся страны и страны с транзитивной экономикой, в том числе и Республику Беларусь. По данным Всемирного банка доля услуг в мировом ВВП увеличилась с 64,2\% в 2000 г. до 69\% в 2015 г. [10]. При этом причины и последствия произошедшего сдвига очень разнообразны, и для их оценки необходимо учитывать также изменения, происходящие внутри этих 
секторов экономики, и взаимосвязь между ними. Зачастую, резкое увеличение доли сектора услуг в мировом хозяйстве связывают с сервисизацией экономики, то есть «возрастанием видов деятельности, нацеленных на обслуживание индивидуальных потребителей» [11]. Такой подход основывается на том, что преимущество, в особенности на первых этапах развития сферы услуг как самостоятельной сферы народного хозяйства, получили такие услуги, как розничная торговля, транспорт, туризм, финансовые услуги. Сервесизация экономики является непосредственным следствием увеличения доходов домашних хозяйств и совместно с технико-технологическим развитием влечет за собой перераспределение доли в структуре ВВП и занятости в сторону сферы услуг.

Возможность формирование в сфере услуг более высокой добавленной стоимости и меньшая степень ее капиталоёмкости по сравнению с промышленным производством привело к снижению к началу XX в. индустриальной активности практически во всех экономически развитых странах и переориентацию экономики на производство услуг, то есть к деиндустриализации. При этом сокращение занятости в промышленном производстве не означает автоматическое пропорциональное увеличение занятости в сфере услуг. О. В. Дьяченко, изучая последствия деиндустриализации в США, пишет: «Первым и наиболее болезненным следствием деиндустриализации стало сокращение производственных рабочих мест. < ..> Сервисные сектора, обслуживающие потребности умирающего производства, также ощутили волны деиндустриализации. В исследованиях американских ученых в середине 1980-х гг. отмечалось, что при потере 1000 рабочих мест в промышленности экономика также лишается 1000 рабочих мест в сервисном секторе» [12]. Таким образом, при деиндустриализации сокращается количество занятых в промышленном производстве, а также в тех отраслях сферы услуг, которые связаны непосредственно с промышленным производством. При этом освободившаяся рабочая сила перераспределяется, как правило, в иные отрасли сектора услуг, что связано с относительной простотой переквалификации работников для этих видов деятельности.

Одной из главных причин увеличения доли услуг в структуре мирового хозяйства А. Айкельпаш называет повышение капиталоемкости промышленного производства. Этот автор пишет: «С каждой новой машиной возрастает продуктивность работника. Это приводит, в том числе к тому, что доля персонала, занятого изготовлением, сокращается, - указывает А. Айкельпаш. - С другой стороны мы не должны забывать про тесные связи с другими предприятиями. Предприятия зачастую покупают промежуточные услуги, которые до этого производили сами». В качестве еще одной возможной причины этот автор называет развитие аутсорсинга, вследствие которого статистически некоторые виды деятельности, ранее учитывающиеся в промышленном производстве, теперь отражаются в сфере услуг. «В общем и целом, - подводит итог А. Айкельпаш, - можем исходить из того, что сокращение доли непосредственно производства сводится к тому, что процесс производства становится все более капиталоемким» [13]. При повышении капиталоемкости производства происходит значительное изменение в структуре занятости, что, зачастую, трактует как деиндустриализаци. К Шваб указывает на наличие двух конкурирующих воздействия технологии на занятость: «Во-первых, существует дизруптивный эффект, поскольку обусловленный технологией прорыв и автоматизация заменяют труд на капитал, лишая рабочих заработка или вынуждая их применять свою квалификацию в другом месте. Во-вторых, указанный дизруптивный эффект сопровождается эффектом капитализации, когда спрос на новые товары и услуги повышается и обусловливает создание новых рабочих мест, компаний и даже отраслей» [14, с. 31]. Исходя из расширенной трактовки деиндустриализации как «значительного уменьшения роли производящих отраслей в структуре экономики государства, в результате глубокого кризиса или переориентации на разви- 
тие других направлений или отраслей, например, сферы услуг, туризма и т.п.» [15], увеличение доли сектора услуг в структуре ВВП и занятости, обусловленное увеличением капиталоемкости промышленного производства, на наш взгляд, не связано с деиндустриализацией экономики.

Однако причиной резкого увеличения доли сектора услуг, в особенности в экономически развитых странах, таких как США, Великобритания, явилась не только интенсификация промышленного производства, но и активное развитие финансовоспекулятивных услуг. Лидерство третичного сектора, обеспечивающееся, в первую очередь, за счет этих услуг, привело к оттоку капитала (человеческого, финансового) и ослаблению промышленного сектора. Виртуализация и рост фиктивного капитала, не связанного с реальным производством, стали причиной неустойчивости национальных и глобальной экономик. После мирового финансово-экономического кризиса 20082009 гг. в США и некоторых странах Западной Европы начался (или, в случае с Германией, продолжилась) процесс, обратный деиндустриализации, - реиндустриализация, отличающейся интенсивным развитием национального промышленного производства, преимущественно высокотехнологичных и наукоемких отраслей. Основной причиной изменения промышленной политики наиболее крупных экономик мира О. В. Дьяченко справедливо считает стремление к технологическому лидерству. «Противоречия между Россией, США и странами Запада можно объяснить стремлением к монополизации высокотехнологичных ниш в областях критических технологий (живые системы, медицина, биохимия, генетика, химические технологии, наноматериалы, космические технологии, технологии автоматизации производства и др.) - пишет этот автор. - Все мировые игроки понимают: кто первый займет эти конкурентные позиции, тот и будет принимать решения о распределении и присвоении большей части глобального капитала в недалеком будущем» [12].

Обратимся к статистическим данным, демонстрирующим изменения структуры национальных ВВП отдельных стран. На рисунке 1 представлена динамика доли промышленного производства в ВВП с 2008 по 2015 гг. по данным Всемирного банка. Горизонтальной линией обозначена доля промышленного производства в ВВП рассматриваемой страны в 2000 г.

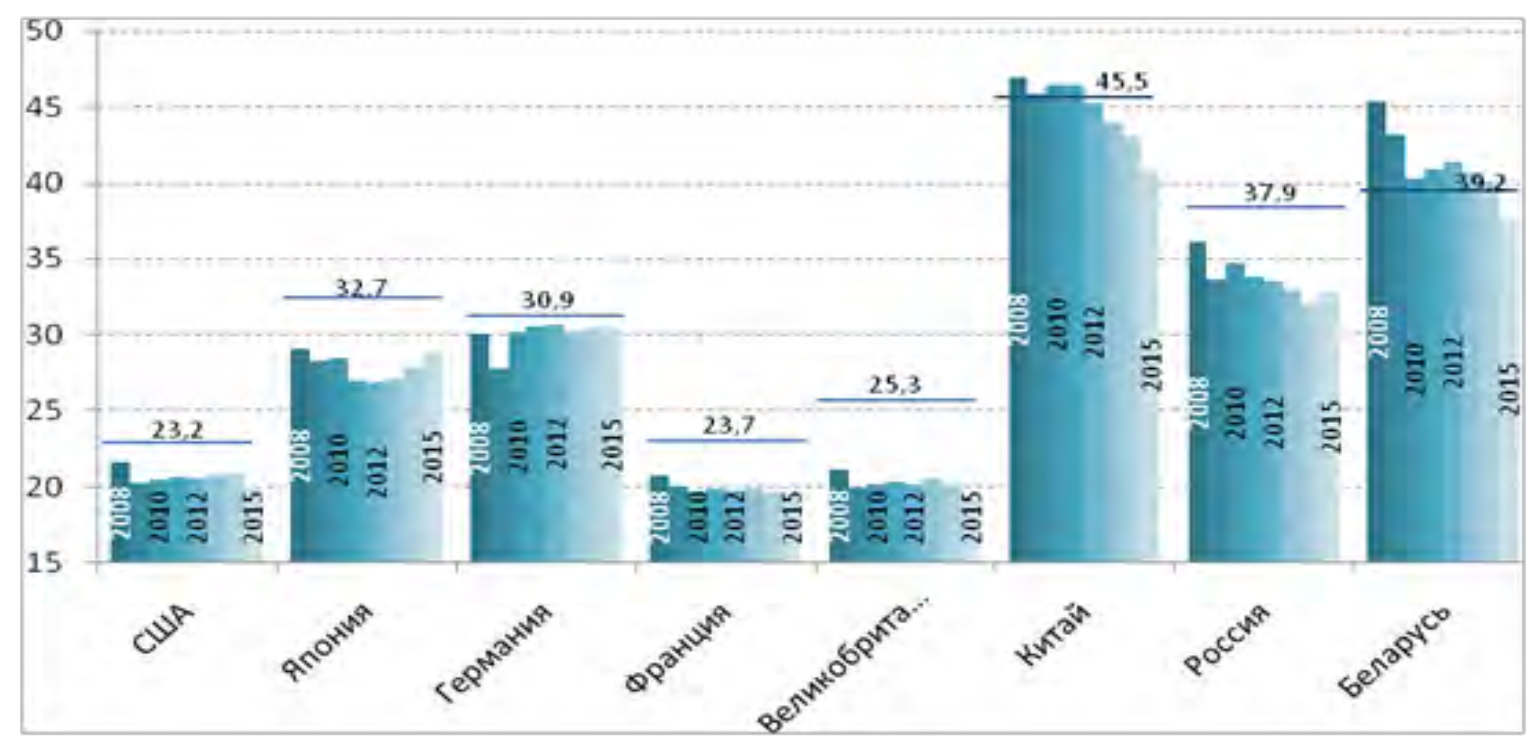

Рисунок 1 - Доля промышленного производства в ВВП в 2008-2015 гг. (горизонтальной линией - в 2000 г.)

Источник: разработка автора на основании данных [16] 
Благодаря относительно недорогой рабочей силе (по показателю затраты на рабочую силу на единицу продукции разрыв в 2006 г. между Китаем и США составлял 17,1 долл. США, к 2014 г. разрыв сократился до 9,2 долл. США [17, с. 30]), самой дешевой электроэнергии среди мировых промышленных лидеров (2 долл. США за миллион британских тепловых единиц, для сравнения в Южной Корее - 16 долл. США, в Китае - 14 долл. США [17, с. 30]), невысокой стоимости капитала и конкурентоспособности экспорта (во многом за счет слабости доллара) в США с 2010 г. по 2014 г. доля промышленного производства в структуре ВВП выросла с 20,2\% до 20,9\% [16]. Рост был обеспечен как созданием новых и развитием имеющихся промышленных предприятий, так и решорингом, то есть возвращением на территорию США производственных мощностей, перенесенных ранее за границу.

Финансово-экономический кризис отрицательно сказался также и на экономическом развитии Европейского союза, в том силе и промышленности. В первую очередь пострадали такие секторы промышленности, как производство электрооборудования, компьютеров, оптики, при этом для фармацевтической и пищевой промышленности, неавтомобильного транспортного машиностроения было характерно устойчивое развитие [17, с. 33]. В целом же промышленное производство оказалось более устойчивым к кризисным явлениям, что побудило Европейский союз к принятию новой концепции экономического развития, получившей название «от рецессии к реиндустриализации» [17, с. 33]. К 2020 г. поставлена цель, увеличить удельный вес промышленности в совокупном ВВП до $20 \%$ [17, с. 33]. Однако методы и инструменты реализации принятой концепции, а также ее темп будет отличаться в зависимости от уровень социальноэкономического развития и особенностей структуры их экономик.

Во Франции в послекризисный период только в 2011 г. и 2013 г. был зафиксирован рост доли промышленного производства (достиг 19,8\%), в 2014-2015 гг. этот показатель снова начал сокращаться и упал до 19,5\%. В Великобритании доля промышленного производства в ВВП уже в 2010 г. увеличилась до 20,1\%, в 2011 г. - до 20,3\%, и после небольшого спада в 2012 г. (20,1\%) достигла в 2013 г. 20,5\%. Однако в 2014 г. начался спад промышленного производства, и его доля в ВВП страны к 2015 г. снизилась до 19,4\%. В Германии на протяжении трех послекризисных лет наблюдался устойчивый рост доли промышленности в структуре ВВП: в 2010 г. - 30,2\%, в 2011 г. 30,6\%, в 2012 г. - 30,\%. В 2013 г. этот показатель сократился до 30,2\%, после чего снова начал расти и в 2014-2015 гг. составил 30,5\%. Примечательным является то, что, преодолев кризисный спад уже в 2010 г. (в 2009 г. доля промышленности в ВВП составила 27,8\%), доля промышленности Германии сохранялась на достаточно высоком уровне и не опускалась ниже показателей 2008 г. (30,1\%). В то время, как доля промышленного производства в структуре ВВП, Франция так и не достигла показателей уровня 2008 г. (20,7\%), а Великобритания, после некоторого подъема, в 2015 г. сократила долю промышленности в своем ВВП по сравнению с 2008 г. на 0,7\% (с 21,1\% в 2008 г. до 19,4\% в 2015 г.) [16]. О. В. Дьяченко справедливо отмечает: «Германия осталась одной из немногочисленных стран-членов ЕС, которая с начала XXI в. смогла не только сохранить высокую долю промышленности $(22,5 \%)$, но и увеличит объем промышленной продукции на 23,5 \%. ... Либерально-монетаристская модель уступила более прогрессивной - производственно-социальной, предполагающей приоритетное развитие промышленного производства, интегрированного в международные цепочки создания стоимости» [12, с. 65].

Вместе с тем сокращение доли промышленного производства в структуре ВВП не всегда связано с деиндустриализацией, а может быть обусловлено абсолютным приростом производства услуг. На рисунке 2 представлен объем услуг (оптовая и рознич- 
ная торговля, общественное питание, транспорт, государственное управление, финансы, бытовое обслуживание, услуги профессионального характера (например, инженерные, проектные услуги), здравоохранение, образование, услуги в сфере недвижимости [18]), оказанных с 2008 г. по 2015 г., в некоторых стран по данным Всемирного банка (в текущих ценах, долл. США).

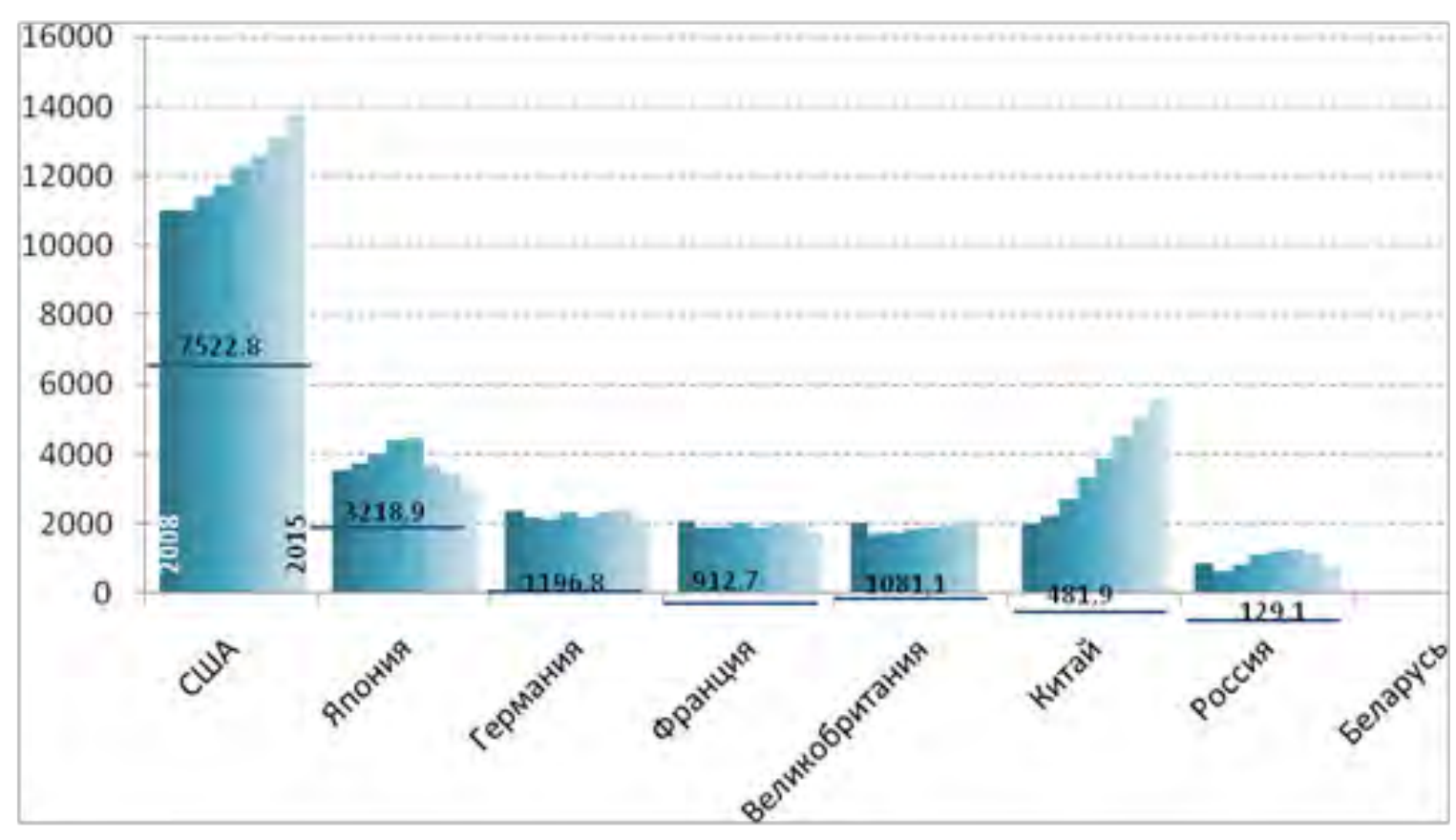

Рисунок 2 - Объем сферы услуг в текущих ценах в 2008-2015 гг.

(горизонтальной линией - в 2000 г.)

Источник: разработка автора на основании данных [18]

За рассматриваемы период в США, занимающих первое место в мире по объему оказываемых услуг, начиная с 2009 г. объем услуг постоянно возрастал: данный показатель составил в 2009 г. 11014 млрд. долл. США, а к 2015 г. увеличился до 13780 млрд. долл. США [18]. Соотнесение этих показателей с рассматриваемой ранее динамикой доли промышленного производства в ВВП США, которая в 2009-2014 гг. стабильно росла, что является также подтверждением проводимой реиндустриализации в США.

Однако в странах-участницах Европейского союза тенденция увеличения объема оказываемых услуг была не столь однозначна. Во Франции, в частности, в послекризиный период объем услуг варьировался от 1911,2 млрд. долл. США в 2009 г. до максимального значения 2 013,8 млрд. долл. США в 2013 г., после начал сокращаться и достиг в 2015 г. 1 703,1 млрд. долл. США, что на 339,6 млрд. долл. США меньше, чем в 2008 г. Несмотря на более существенное падение объемов оказываемых услуг в первые годы после кризиса (в 2009-2010 гг. объем услуг снизился более чем на 300 млрд. долл. США), Великобритании в 2015 г. удалось достичь показателя в 2 038,6 млрд. долл. США, что даже превысило уровень 2008 г. В Германии за рассматриваемый период объем оказываемых услуг превышал аналогичный показатель Франции и Великобритании, тем не менее наблюдался существенный спад. Только в 2014 г. объем оказываемых услуг в Германии достиг уровня 2008 г. и составил 2398 млрд. долл. США (в 2008 г. - 2 330,7 млрд. долл. США). 
Несмотря на существенные колебания объемов услуг, оказываемых во Франции в 2008-2015 гг., доля сферы услуг в структуре ВВП оставалась почти неизменной: она варьировалась от 78,5\% в 2008 г. до 78,8\% в 2015 г. В Великобритании доля сферы услуг в ВВП изменялась более динамично: после спада в 2008 г., когда данный показатель составил 78,2\%, в 2009 г. доля услуг в ВВП увеличилась на 1,3\% (до 79,5\%). Далее снижение и повышение доли услуг в ВВП Великобритании чередовались в диапазоне от 79\% в 2011 г. до 79,9\% в 2015 г. В Германии же в 2009 г. доля сферы услуг в ВВП составила $71,5 \%$, после чего с колебаниями то в сторону снижения, то в сторону повышения, все же упала к 2015 г. до 68,9\%.

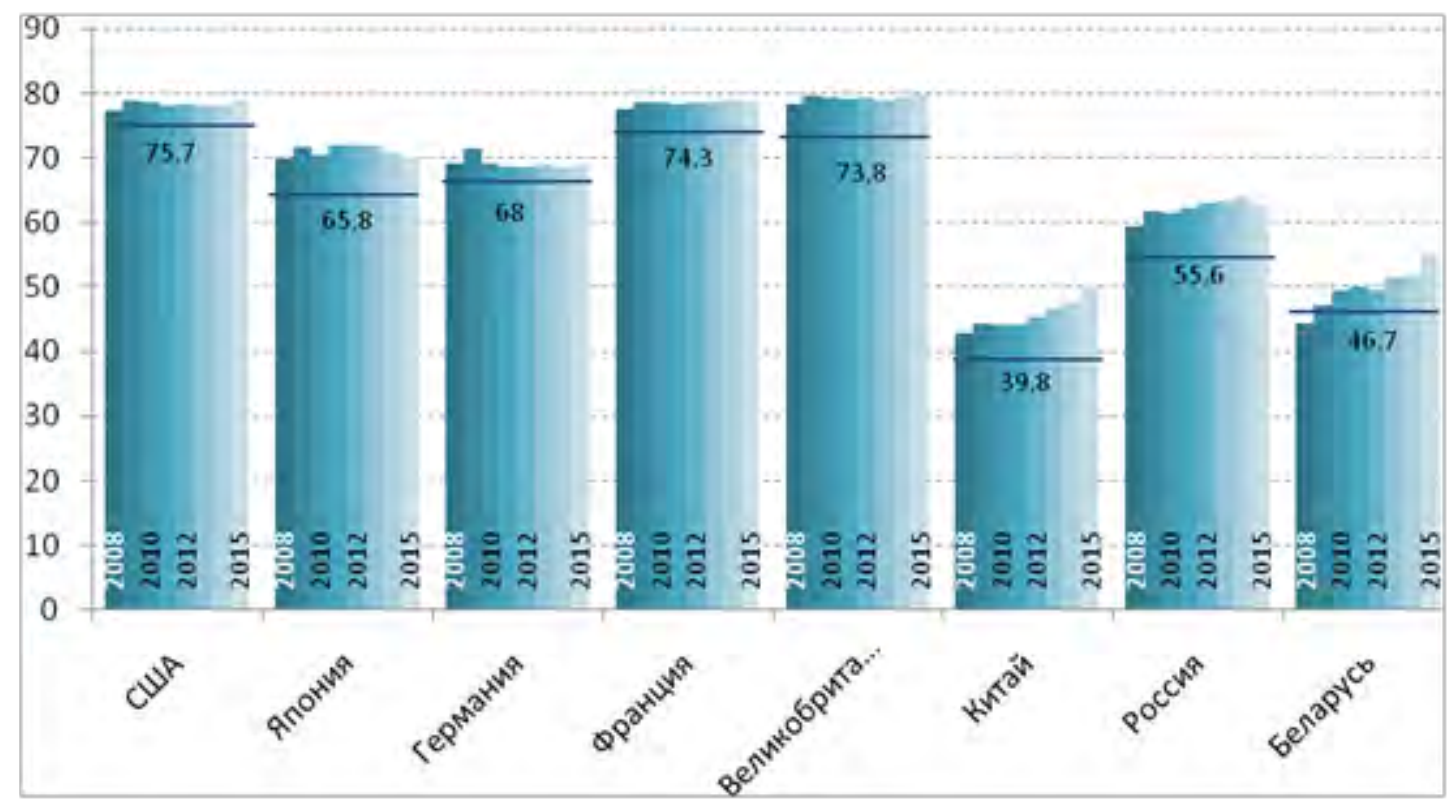

Рисунок 3 - Доля сферы услуг в ВВП в 2008-2015 гг. (горизонтальной линией - в 2000 г.) Источник: разработка автора на основании данных [18]

Таким образом, проведенный анализ динамики структуры ВВП и объема оказываемых услуг показывает большую чувствительность экономики Европейского союза (по сравнению с экономикой США) к кризисным явлениям, негативно повлиявших и на промышленное производство, и на сферу услугу. При этом, однако, экономика Германии оказалась более устойчивой к глобальному финансово-экономическому кризису 2008-2009 гг., что большинство специалистов объясняют развитостью промышленности, ее экспортоориентированностю и конкурентоспосбностью немецкой промышленной продукции на международном уровне. Д. Эдлер и А. Айкельпаш, однако, обращают внимание на структурные изменения, произошедшие внутри самого промышленного производства: «Мы установили, что деятельность, связанная непосредственно с изготовлением и производством, теряет значение, в то время как услуги промышленного характера набирают вес» [13]. И именно сфера услуг промышленного характера оказалась наиболее устойчивой: «Во время кризиса 2008/2009 гг. занятость в обрабатывающей промышленность существенно сократилась, но к 2012 г. уже достигла уровня 2008 г. и с этого момента росла дальше. В сфере услуг промышленного характера в узком смысле провал занятости, связанный с кризисом, был преодолен уже в 2010 г. В сфере услуг промышленного характера в широком смысле кризис был практически не заметен» [19, с. 23]. 
Сегодня в Германии только половина занятых в промышленном производстве участвуют непосредственно в производственном процессе [19, с. 24]. Д. Эдлер и А. Айкельпаш отмечает высокую степень гетерогенности сектора услуг: «В отношении так называемой терциализации речь идет, в первую очередь, о возрастании информационных услуг и таких коммерческих услуг, как НИОКР, технических, финансовых консалтинговых услуг по юридическим и налоговым вопросам, рекламы и маркетинговых исследований, торговли и транспорта» [20, с. 17]. По данным проведенных ими исследований около $30 \%$ услуг являются промежуточным продуктом потребления для промышленного производства, при этом чуть меньше $23 \%$ услуг потребляется непосредственно обрабатывающей промышленностью [20, с. 19]. Эти авторы приходят к выводу, что «рост сектора услуг обусловлен в большей степени растущим спросом предприятий (промышленных предприятий и предприятий сферы услуг) и в меньшей спросом домашних хозяйств» [20, с. 17].

Таким образом, внутренние изменения характера производства, а именно возрастание значения услуг промышленного характера, также приводят к росту сектора услуг, не связанному, однако, с деиндустриализацией экономики. Сегодня рост сферы услуг обеспечивается не столько за счет спроса домашних хозяйств на услуги как конечные потребительские товары, что было характерно для сервисизации экономики, начавшейся в середине XX века, или за счет финансово-спекулятивного сектора, а во многом за счет спроса на услуги промышленного характера, представляющие собой промежуточное потребление промышленного производства.

Статистически процесс терциализации промышленности отражается как увеличение количества занятых в сфере услуг промышленного характера и возрастание доли этих услуг в добавленной стоимости промышленной продукции. Исследования, проведенные немецкими экономистами, показали, что в среднем в обрабатывающей промышленности доля услуг промышленного характера (по количеству занятых) составляет около $52 \%$. К отраслям с наибольшей долей услуг промышленного характера относятся: фармацевтика - 70,7\%, производство электрооборудования, электронного и оптического оборудования - 66,4\%, швейное производство - 64,2\%. В отраслях с наименьшей долей услуг промышленного характера этот показатель составляет не менее $30 \%$ : издательская деятельность - 41,1\%, целлюлозно-бумажное производство - 37,8\%, производство готовых металлических изделий - 31,9\% [21].

Вместе с тем терциализация промышленности свидетельствует также и об изменении значения услуг промышленного характера. Традиционно деятельность, связанная с услугами промышленного характера, относилась к вспомогательным процессам производства. Так, например, разрабатывая проблематику классификации промышленных товаров Д. О. Ямпольская отмечает: «Выделяют три группы этих товаров (товаров производственного назначения - примечание Ю. М.): материалы и детали, капитальное имущество и вспомогательные материалы и услуги» [22, с. 73]. При этом к первой группе (группе А) относят сырье, полуфабрикаты и детали (полностью переносят свою стоимость на выпускаемый продукт, как правило, относятся к оборотным средствам производства), ко второй (группе Б) - здания, сооружения и стационарное технологическое оборудование (основные средства производства), к третьей группе (группе В) вспомогательные сырье и материалы, деловые услуги различного рода. Описывая группу В, этот автор указывает в качестве основной характеристики, что «оборудование этого типа вообще не становится частью готового изделия» [22, с. 75]. Однако сегодня функциональное назначение услуг промышленного характера значительно расширилось, а вместе с тем увеличилось и качественное разнообразие услуг промышленного характера. Н. И. Ивашкова указывает на то, что для промышленного предприятия 
рассматриваемые нами услуги являются «во-первых, гибким и восприимчивым инструментом товарной политики в комплексе маркетинга предприятия; во-вторых, функциональным элементом его производственной логистической системы; в-третьих, потоковым процессом взаимодействия систем производителя и потребителя промышленной продукции» [23, с. 74]. Кроме выделенных Н. И. Ивашковой функций услуг промышленного характера - маркетинговой, производственно-логистической и организационной - на наш взгляд, еще одной важнейшей функцией услуг промышленного характера является разработка самой промышленной продукции (НИОКР, дизайн, инжиниринг и т.д.). В контексте четвертой промышленной революции названные выше функции услуг промышленного характера приобретают новую форму реализации, зачастую, новое значение.

Создание цифровых компьютеров и последующее развитие информационных технологий характеризовали третью промышленную революцию, о свершении которой можно говорить и в Беларуси. На Всемирном экономическом форуме в Давосе, проходящем в январе 2017 г., большинство экономистов сошлись во мнении, что «человечество стоит на краю новой технологической революции» [24], а именно четвертой промышленной революции. К. Шваб выделяет в качестве основных черт четвертой промышленной революции «"вездесущий" и мобильный Интернет, миниатюрные производственные устройства (которые постоянно дешевеют), искусственный интеллект и обучающиеся машины» $[14$, с. 10$]$.

Зачастую четвертую промышленную революцию рассматривают как продолжение третьей цифровой промышленной революции. По этому поводу К. Шваб отмечает: «Цифровые технологии, основанные на аппаратном и программном обеспечении и сетях, не являются новшеством, но с каждым годом уходя все дальше от третьей промышленной революции, становятся более усовершенствованными и интегрированными, вызывая трансформацию общества и глобальной экономики» [14, с. 10]. Ключевым же отличием новой промышленной революции являются киберфизические системы: «Именно синтез этих технологий (от расшифровки информаџии, записанной в человеческих генах до нанотехнологий, от возобновляемых энергоресурсов до квантовых вычислений - примечание Ю. М.) и их взаимодействие в физических, цифровых и биологических доменах составляют фундаментальное отличие четвертой промышленной революции от всех предыдущих революций» [14, с. 11]. Внедрение киберфизических систем, позволяющих связать все производственные процессы в одну сеть в режиме реального времени, способных самонастраиваться и самообучаться, нацелено, с одной стороны, на повышение эффективности производства, в том числе за счет уменьшения ошибок, а с другой - на повышение уровня адаптивности промышленной продукции и производства к быстро меняющимся потребностям рынка. Формирование такой гибкой, интегрированной и информативной производственной системы становится возможным благодаря использованию техники и технологий четвертой промышленной революции - беспилотные транспортные средства, 3D-печать, робототехника, новые материалы, новые способы сбора и анализа данных (BogData, DataScience), интернет вещей $[14$, с. $16 ; 25$, с. 60$]$.

Раскрывая содержание четвертой промышленной революции и ее последствия для бизнеса и государства, К. Шваб отмечает: «Чтобы обеспечивать конкурентоспособность, компании и страны должны внедрять инновации во всех их формах, это означает, что стратегии, преимущественно направленные на снижение затрат, окажутся менее эффективными, чем стратегии, основанные на более инновационных способах предложения продуктов и услуг» [14, с. 30]. Иными словами, конкурентоспособность продукции в эпоху четвертой промышленной революции обеспечивается за счет использова- 
ния инноваций, направленных, в первую очередь, на качественное изменение производимой продукции, а не на снижение затрат. В связи с этим особое значение приобретают услуги по разработке и внедрению продукции в производство (НИОКР, дизайн и т.д.) и услуги, сопровождающие промышленную продукцию (маркетинговые услуги, проектирование, консалтинг, профессиональное обучение и т.д.).

Клиентоориентированность промышленной продукции определяет направления изменения бизнес-процессов, в том числе и самих производственных процессов, делая его более гибким и специализированным. «Чтобы удовлетворить все более разнообразные запросы покупателей, необходимо прикладывать все больше усилий для модернизации ассортимента продукции и клиентских услуг, освоение дополнительных рынков труда требует больше инвестиций в маркетинг, рекламу и продажи, - пишет М. Громлинг. - Оптимизация возрастающих, становящихся все более комплексными, бизнеспроцессов внутри предприятия и с партнерами требуют больше планирования и контроля, возрастающие требования к работникам - повышение требований к навыкам обучения» [26, с. 9].Технологии же четвертой промышленной революции обеспечивают возможность все более глубоко взаимопроникновения бизнес-процессов на фоне их автоматизации и непрерывного контакта производителей и потребителей, в результате трансформируются традиционные и возникают новые формы производства и торговли. Речь идет об «умных заводах», посредствам которых, как отмечает К. Шваб, «четвертая промышленная революция создает мир, в котором виртуальные и физические системы производства гибко взаимодействуют между собой на глобальном уровне. Это обеспечивает полную адаптацию продуктов и создание новых операционных моделей» [14, с. 11]. Новый тип промышленного производства, базирующийся на технологиях промышленного интернета вещей, больших данных (BigData), полной автоматизации производства, позволяет не просто интенсифицировать производственный процесс (повысить производительность труда, снизить уровень брака), но и сформировать единую глубоко интегрированную цепочку создания стоимости, координирующую деятельность всех ее участников(от разработчиков и изготовителей до конечных потребителей), и при необходимости оперативно адаптирующуюся к новым потребностям рынка. Автоматизация логистических процессов и развитие электронной торговли изменяет формы реализации промышленной продукции и способствует еще большей глобализации рынка. В контексте таких изменений производственных процессов и бизнеспроцессов роль услуг промышленного характера, как услуг по разработке и внедрению продукции в производство, так и услуг, сопровождающих производственную продукцию, будет и дальше возрастать, что на макроуровне отразиться как в увеличение доли добавленной стоимости промышленной продукции, создаваемой этими услугами, так и в возрастании количества занятых в этих сферах производства. К. Шваб справедливо считает, что переход от простой цифровизации (третья промышленная революция) к инновациям, базирующимся на комбинациях технологий (четвертая революция), вынуждает компании пересмотреть свое отношение к тому, как они работают» [24]. Тенденция изменения промышленного производства в сторону клиентоориентированности и развитие технологии четвертой промышленной революции будут способствовать перенесению «центра тяжести» промышленных предприятий с изготовления на услуги промышленного характера, за счет которых и будут формироваться основные конкурентные преимущества промышленной продукции. 


\section{ВЫВОДЫ}

Проведенное исследование позволяет сделать следующие выводы: основными источниками роста сферы услуг, приведшими к доминированию этого сектора в структуре мирового ВВП и занятости, являются: сервисизация экономики, увеличение капиталоемкости промышленного производства, рост финансово-спекулятивного сектора; увеличение доли третичного сектора в структуре ВВП и занятости национальной экономики не является достаточным признаком деиндустриализации экономики; конкурентоспособная экспортноориентированная промышленность и услуги промышленного характера являются наиболее устойчивыми к глобальным финансово-экономическим кризисам; в условиях реиндустриализации развитие сектора услуг обусловлено не только (и не столько) увеличением спроса со стороны домашних хозяйств, а ростом спроса на услуги промышленного характера; в контексте четвертой промышленной революции значение услуг промышленного характера в формировании конкурентоспособности промышленных предприятий увеличивается, поскольку именно благодаря этим услугам может быть организовано эффективное производство нового типа («умные заводы») и реализована клиентоориентированная (в широком смысле) политика предприятия.

\section{СПИСОК ИСПОЛЬЗОВАННЫХ ИСТОЧНИКОВ}

1. Мелешко, Ю. В. Понятие и экономический механизм оказания услуг промышленного характера/ Ю. В. Мелешко// Известия Гомельского государственного университета имени Ф. Скорины. Социально-экономические и общественные науки. - Гомель: Известия Гомельского государственного университета имени Ф. Скорины, 2016. - №5 (98). - C.118-123.

2. Мелешко, Ю. В. Системообразующие принципы развития услуг промышленного характера/ Ю. В. Мелешко //Устойчивое развитие экономики: состояние, проблемы, перспективы: сборник трудов ХІмеждународной научно-практической конференции, УО «Полесский государственный университет», г. Пинск, 21 апреля 2017 г./ Министерство образования Республики Беларусь [и др.]; редкол.: К. К. Шебеко[и др.]. Пинск: ПолесГУ, 2017. - С.84-86.

3. Мелешко, Ю. В. Экономический механизм оказания услуг промышленного характера: условия и направления развития [Электронный ресурс] / Ю. В. Мелешко // Развитие экономики, политики, социума: состояние, проблемы, перспективы: сборник научных статей. - 2017. - №6. - 119 с. - С.59-68.

4. Солодовников, С. Ю. Классы и классовая борьба в постиндустриальном обществе: методологические основы полит-экономического исследования/ С. Ю. Солодовников. - Минск: БНТУ, 2014. - 378 с.

5. Солодовников, С. Ю. Феноменологическая природа взаимообусловленности экономической конкурентоспособности и социального капитала Беларуси и Украины/ С. Ю. Солодовников// Экономическая наука сегодня: сборник научных статей. - 2015. № 3. - С. 23-34.

6. Солодовников, С. Ю. Теоретико-методологические основы исследования социального капитала как политико-экономического феномена / С. Ю. Солодовников// Экономическая наука сегодня: сборник научных статей. - 2017. - №5. - С.6-56.

7. Солодовников, С. Ю. Категория «социальный класс» в контексте политикоэкономического исследования П.А. Сорокина и Л.Н. Гумилева / С. Ю. Солодовников // Экономическая наука сегодня: сборник научных статей. - 2014. - №2. - С.24-50. 
8. Солодовников, С. Ю. Новые ресурсы экономической модернизации/ С. Ю. Солодовников, Л. П. Васюченок, Ю. В. Мелешко, А. Н. Тур; под ред. С. Ю. Солодовникова. - Минск: БНТУ, 2016. - 324 с.

9. Сергиевич, Т. В. Некоторые политико-экономические аспекты исследования трудовых отношений в Республике Беларусь на современном этапе/ Т. В. Сергиевич// Экономическая наука сегодня: сборник научных статей. - 2017. - №4. - С.278-286.

10. Services, etc., value added (current US\$)(NV.SRV.TETC.CD)// The World Bank. - Режим доступа: http://databank.worldbank.org/data/ reports.aspx?source=worlddevelopment-indicators.

11. Скоробогатова, Т.Н. Сервизация экономики как сформировавшаяся парадигма [Электронный peсурс]/ Т.Н. Скоробогатова // Культура народов Причерноморья. - 2007. - № 104. - С.67-71.

12. Дьяченко, О. В. Мировые тренды реиндустриализации: первоначальный опыт и современные противоречия/ О. В. Дьяченко, Е. С. Зарубежнов // Экономическое возрождение России. - 2015. - №3. - С.62-75.

13. Sechs Fragen an Alexander Eickelpasch: «Immer weniger Industriebeschäftigte arbeiten in der Fertigung»// DIW Wochenbericht. - 2014. - Nr. 33.-S. 771.

14. Шваб, К. Четвертая промышленная революция/ К. Шваб. - М.: Эксмо, 2016. -208 c.

15. Деиндустриализация [Электронный ресурс]// Словарь бизнес-терминов. Режим доступа: http://dic.academic.ru/dic.nsf/business/3272.

16. Popular Indicators// The World Bank. - Режим доступа: http://databank.worldbank.org/data/reports.aspx?Code=NY.GDP.MKTP.KD.ZG\&id=1ff4a49 8\&report_name $=$ Popular-Indicators\&populartype $=$ series\&ispopular $=\mathrm{y}$

17. Побываев, С. А. Реиндустриализация в США и ЕС/ С. А. Побываев, С. А. Толкачев// Мир новой экономики. - 2015. - №2. - С.29-36.

18. Services, etc., value added (current US\$)(NV.SRV.TETC.CD)// The World Bank. - Режим доступа: http://databank.worldbank.org/data/ reports.aspx?source=worlddevelopment-indicators.

19. Eickelpasch, A. Industrie und industrienahe Dienstleistungen in der Region Frankfurt-Rhein-Main/ A. Eickelpasch, R. Behrend und D. Krüger-Röth. - Berlin: DIW Berlin, 2017. - $137 \mathrm{~S}$.

20. Edler, D. Die Industrie - ein wichtiger Treiber der Nachfrage nach Dienstleistungen/ D. Edler, A. Eickelpasch// DIW Wochenbericht. - 2013. - Nr. 34. - S. 16-23.

21. Eickelpasch, A. Funktionaler Strukturwandel in der Industrie: Bedeutung produktionsnaher Dienste nimmt zu/ A. Eickelpasch// DIW Wochenbericht/ - 2014. - Nr. 33.2014. S. 759-770.

22. Ямпольская, Д. О. Проблемы и перспективы классификации промышленных товаров/ Д.О. Ямпольская// Маркетинговое сопровождение промышленных товаров российского происхождения на рынки стран Азии, Африки и Латинской Америки: сборник научных трудов. - 2016. - С.69-86.

23. Ивашкова, Н. И. Маркетинговый подход к развитию промышленных сервисных услуг/ Н. И. Ивашкова, Е. И. Карякин // Инициативы XXI века. - 2013. - №4. C. $73-76$.

24. 4-я промышленная революция в Давосе [Электронный ресурс]// Эксперт ONLINE. - Режим доступа: http://expert.ru/2016/01/21/chetvertaya-promyishlennayarevolyutsiya/. - Дата доступа: 02.09.2017. 
25. Хуснуллова, А. Р. Четвертая промышленная революция и ее социальноэкономические последствия/ А. Р. Хуснуллова, С. Г. Абсалямова// Фундаментальные и прикладные исследования кооперативного сектора экономики. - 2016. - №2. - С. 59-63.

26. Grömling, M.: Die Tertiarisierung der deutschenWirtschaft - Was treibt den Strukturwandel an, und was bringter? WirtschaftswissenschaftlicheBeiträge des LehrstuhlsfürVolkswirtschaftslehre, Wirtschaftsordnung und Sozialpolitik. - 2006. - № 87. - S. 9.

\section{REFERENCES}

1. Meleshko, Ju. V. Ponjatie i jekonomicheskij mehanizm okazanija uslug promyshlennogo haraktera/ Ju. V. Meleshko// Izvestija Gomel'skogo gosudarstvennogo universiteta imeni F. Skoriny. Social'no-jekonomicheskie i obshhestvennye nauki. - Gomel': Izvestija Gomel'skogo gosudarstvennogo universiteta imeni F. Skoriny, 2016. - №5 (98). - S.118-123.

2. Meleshko, Ju. V. Sistemoobrazujushhie principy razvitija uslug promysh-lennogo haraktera/ Ju. V. Meleshko //Ustojchivoe razvitie jekonomiki: sostojanie, pro-blemy, perspektivy: sbornik trudov XImezhdunarodnoj nauchno-prakticheskoj konfe-rencii, UO «Polesskij gosudarstvennyj universitet», g. Pinsk, 21 aprelja 2017 g./ Ministerstvo obrazovanija Respubliki Belarus' [i dr.]; redkol.: K. K. Shebeko[i dr.]. - Pinsk: PolesGU, 2017. - S.84-86.

3. Meleshko, Ju. V. Jekonomicheskij mehanizm okazanija uslug promyshlen-nogo haraktera: uslovija i napravlenija razvitija [Jelektronnyj resurs] / Ju. V. Melesh-ko // Razvitie jekonomiki, politiki, sociuma: sostojanie, problemy, perspektivy: sbornik nauchnyh statej. 2017. - №6. - 119 s. - S.59-68.

4. Solodovnikov, S. Ju. Klassy i klassovaja bor'ba v postindustrial'nom obshhestve: metodologicheskie osnovy polit-jekonomicheskogo issledovanija/ S. Ju. Solo-dovnikov. Minsk: BNTU, 2014. - $378 \mathrm{~s}$.

5. Solodovnikov, S. Ju. Fenomenologicheskaja priroda vzaimoobuslovlennosti jekonomicheskoj konkurentosposobnosti i social'nogo kapitala Belarusi i Ukrainy/ S. Ju. Solodovnikov// Jekonomicheskaja nauka segodnja: sbornik nauchnyh statej. - 2015. - № 3. - S. 23-34.

6. Solodovnikov, S. Ju. Teoretiko-metodologicheskie osnovy issledovanija social'nogo kapitala kak politiko-jekonomicheskogo fenomena / S.Ju. Solodovnikov// Jekonomicheskaja nauka segodnja: sbornik nauchnyh statej. - 2017. - №5. - S.6-56.

7. Solodovnikov, S. Ju. Kategorija «social'nyj klass» v kontekste politikojekonomicheskogo issledovanija P.A. Sorokina i L.N. Gumileva / S. Ju. Solodovnikov // Jekonomicheskaja nauka segodnja: sbornik nauchnyh statej. - 2014. - №2. - S.24-50.

8. Solodovnikov, S. Ju. Novye resursy jekonomicheskoj modernizacii/ S. Ju. Solodovnikov, L. P. Vasjuchenok, Ju. V. Meleshko, A. N. Tur; pod red. S. Ju. Solodovnikova. Minsk: BNTU, 2016. - $324 \mathrm{~s}$.

9. Sergievich, T. V. Nekotorye politiko-jekonomicheskie aspekty issledova-nija trudovyh otnoshenij v Respublike Belarus' na sovremennom jetape/ T.V. Sergie-vich// Jekonomicheskaja nauka segodnja: sbornik nauchnyh statej. - 2017. - №4. - S.278-286.

10. Services, etc., value added (current US\$) (NV.SRV.TETC.CD)// The World Bank. - Rezhim dostupa: http://databank.worldbank.org/data/ reports.aspx?source=worlddevelopment-indicators

11. Skorobogatova, T. N. Servizacija jekonomiki kak sformirovavshajasja para-digma [Jelektronnyj resurs]/ T. N. Skorobogatova // Kul'tura narodov Prichernomor'ja. - 2007. - № 104. - S.67-71.

12. D'jachenko, O. V. Mirovye trendy reindustrializacii: pervonachal'nyj opyt i sovremennye protivorechija/ O. V. D'jachenko, E. S. Zarubezhnov // Jekonomicheskoe vozrozhdenie Rossii. - 2015. - №3. - S.62-75. 
13. Sechs Fragen an Alexander Eickelpasch: «Immer weniger Industriebeschäftigte arbeiten in der Fertigung»// DIW Wochenbericht. - 2014. - Nr. 33.-S. 771.

14. Shvab, K. Chetvertaja promyshlennaja revoljucija/ K. Shvab. - M.: Jeksmo, 2016. $-208 \mathrm{~s}$.

15. Deindustrializacija [Jelektronnyj resurs]// Slovar' biznes-terminov. - Rezhim dostupa: http://dic.academic.ru/dic.nsf/business/3272.

16. Popular Indicators// The World Bank. - Rezhim dostupa: http://databank.worldbank.org/data/reports.aspx?Code=NY.GDP.MKTP.KD.ZG\&id=1ff4a49 8\&report_name $=$ Popular-Indicators\&populartype $=$ series\&ispopular $=y$

17. Pobyvaev, S. A. Reindustrializacija v SShA i ES/ S. A. Pobyvaev, S. A. Tolkachev// Mir novoj jekonomiki. - 2015. - №2. - S.29-36.

18. Services, etc., value added (current US\$)(NV.SRV.TETC.CD)// The World Bank. - Rezhim dostupa: http://databank.worldbank.org/data/ reports.aspx?source=worlddevelopment-indicators.

19. Eickelpasch, A. Industrie und industrienahe Dienstleistungen in der Region Frankfurt-Rhein-Main/ A. Eickelpasch, R. Behrend und D. Krüger-Röth. - Berlin: DIW Berlin, 2017. - $137 \mathrm{~S}$.

20. Edler, D. Die Industrie - ein wichtiger Treiber der Nachfrage nach Dienstleistungen/ D. Edler, A. Eickelpasch// DIW Wochenbericht. - 2013. - Nr. 34. - S. 16-23.

21. Eickelpasch, A. Funktionaler Strukturwandel in der Industrie: Bedeutung produktionsnaher Dienste nimmt zu/ A. Eickelpasch// DIW Wochenbericht/ - 2014. - Nr. 33.2014. S. 759-770.

22. Jampol'skaja, D. O. Problemy i perspektivy klassifikacii promyshlen-nyh tovarov/ D. O. Jampol'skaja// Marketingovoe soprovozhdenie promyshlennyh tova-rov rossijskogo proishozhdenija na rynki stran Azii, Afriki i Latinskoj Ameriki: sbornik nauchnyh trudov. 2016. - S.69-86.

23. Ivashkova, N. I. Marketingovyj podhod k razvitiju promyshlennyh ser-visnyh uslug/ N. I. Ivashkova, E. I. Karjakin // Iniciativy XXI veka. - 2013. - №4. - S.73-76.

24. 4-ja promyshlennaja revoljucija $\mathrm{V}$ Davose [Jelektronnyj resurs]// Jekspert ONLINE. - Rezhim dostupa: http://expert.ru/2016/01/21/chetvertaya-promyishlennayarevolyutsiya/. - Data dostupa: 02.09.2017.

25. Husnullova, A. R. Chetvertaja promyshlennaja revoljucija i ee social'nojekonomicheskie posledstvija/ A. R. Husnullova, S. G. Absaljamova// Fundamental'nye i prikladnye issledovanija kooperativnogo sektora jekonomiki. - 2016. - №2. - S.59-63.

26. Grömling, M.: Die Tertiarisierung der deutschenWirtschaft - Was treibt den Strukturwandel an, und was bringter? WirtschaftswissenschaftlicheBeiträge des LehrstuhlsfürVolkswirtschaftslehre, Wirtschaftsordnung und Sozialpolitik. - 2006. - № 87. - S.9.

Статья поступила в редакиию 30 сентября 2017 года. 